\title{
The role of circulating antibody in the control of metastases
}

\author{
M. G. LEWIS 1 \\ From the McGill University Cancer Research Unit, Montreal, Canada
}

It is impossible to understand the neoplastic process without considering the role of the host. This is by no means a new or recent concept since host factors were suggested at the turn of the century by a number of observers (Eve, 1903; Handley, 1907; Ehrlich, 1957). The discovery, however, of specific tumourassociated antigens in carcinogen-induced tumours in the 1950s (Foley, 1953; Prehn and Main, 1957) led to the accumulation of vast amounts of data now available on this subject. One of the present challenges, therefore, is to correlate these with the natural history of the neoplastic process. It is becoming clear that one of the important host factors is immune recognition and reaction against antigens expressed by tumour cells. It is already obvious that this is an extremely complex interrelationship and even a superficial glance shows what appear to be contradictions. To review the whole field in detail is beyond the reasonable bounds of a presentation such as this and it is necessary, therefore, to concentrate on one aspect: the role of circulating antibody in the control of metastases.

Of all the manifestations of the neoplastic process the ability of a malignant tumour to metastasize is one of the most unique and important. Before embarking on a detailed discourse on antibodies and antigens and their relationship to the control of metastases, some evidence must be stated in support of the idea that metastatic spread of tumours can be controlled. Such clinical observations as the inappropriate response to inadequate therapy (Smithers, 1964; Clifford, Singh, Sternswärd, and Klein, 1967; Bodenham, 1968), and the appearance of metastases many years after the appearance of the primary tumour and spontaneous regression (Everson and Cole, 1966) were in fact the original stimuli which led to many of the studies of immune reactions in malignancy. These aspects of the natural history of malignancy in man have been reviewed (HamiltonFairley, 1969; Piessens, 1970; Kopf, 1971) and have been observed by many clinicians and pathologists in the management of patients with cancer. Much

'McIntyre Medical Sciences Buildings, 3655 Drummond St, Montreal, Quebec, Canada of the work quoted in this presentation comes from a series of studies on human malignant melanoma which were carried out in an attempt to answer questions related to differences in the way in whichmetastases develop in malignant melanoma in Ugandan Africans (Lewis and Kiryabwire, 1968). Three types of melanoma were recognized on clinical and pathological criteria: type 1 , in which the tumour remained localized on the sole of the foot for months or years with no detectable spread; type 2 , where spread to the regional lymph nodes and beyond occurred within a matter of weeks or months; and type 3 , in which the patient with a secondary deposit in regional lymph nodes and where at first the primary tumour was not discovered (fig 1). In the type 3 group it was subsequently shown that in many patients the primary tumour had spontaneously regressed (Lewis, 1968). The results of this initial

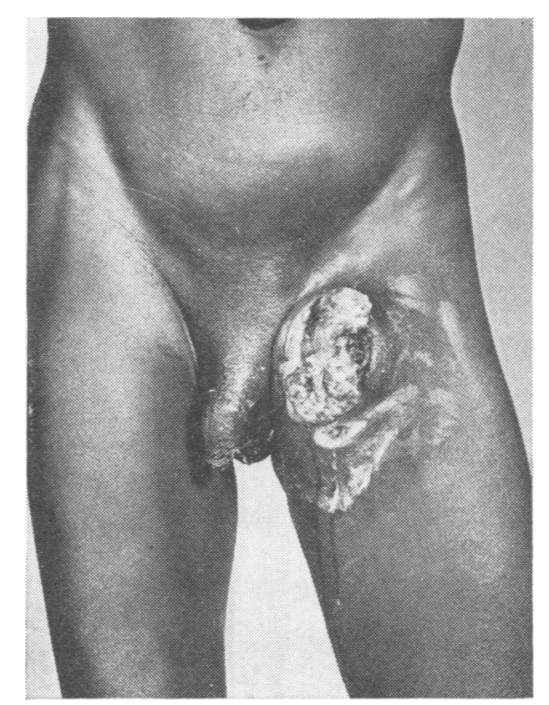

Fig 1 Lymph node metastases from malignant melanoma in an African, with spontaneous regression of primary tumour. 
study showed that there was a factor in the serum of patients with type 1 tumours which was able to cause the death of autologous tumour cells: no such factor was present in control sera of patients with type 2 tumours (Lewis, 1967) (fig 2).

Subsequent studies showed that the serum factor was an immunoglobulin and that the effect could be abolished by inactivating complement from the serum (Lewis, Ikonopisov, Nairn, Phillips, HamiltonFairley, Bodenham, and Alexander, 1969). Following this, evidence using immunofluorescent techniques indicated the presence of antibody in the serum of non-African patients with malignant melanoma (Lewis et al, 1969; Muna, Marcus, and Smart, 1969). A number of reports also indicated the presence of antibody against components of tumour cells in some other human malignancies and in several animal models using techniques such as cytotoxicity (Hellström, Hellström, Pierce, and Bill, 1968; Hellström, Hellström, Pierce, and Yang, 1968; Arpels and Southam, 1969; Nairn, Nind, Guli, Muller, Rolland, and Minty, 1971), immunofluorescence (Klein, Clifford, Klein, and Stjernwärd, 1966; Goldstein, Klein, Pearson, and Clifford, 1969; Muna et al, 1969; Nairn et al, 1971), immunodiffusion (McKenna, Sanderson, and Blakemore, 1964; Gold and Freedman, 1965; Gold, 1967; Jehn, Nathanson, Schwartz, and Skinner, 1970), electrophoresis, growth (colony) inhibition (Hellström, 1967), and complement fixation (Armstrong, Henle, and Henle, 1966). All of these techniques and results have been extensively reviewed elsewhere and each has its own advantages and disadvantages, particularly in the type of cell preparation needed to demonstrate the reaction and the degree of quantitation available. The problem, however, is similar in all situations where 'autoantibodies' are detected. It is necessary to know the particular antigen component of the malignant cell that evokes the particular antibody and the relationship between such antibodies and antigens in terms of the actual disease process. It is after all well known both in bacterial, viral, and protozoal disease, and in so-called autoimmune diseases, that the mere presence of antibody in no way indicates a causal relationship with the disease process. It is possible to have antibodies against components of bacteria which, in fact, do not prevent the bacteria from multiplying or spreading. This is particularly true in situations where the antibody is produced against an exotoxin. This does not mean, however, that antibody is of no significance since the protection against such toxins may in many ways be more important than the prevention or the killing of the bacteria themselves. I would like, therefore, to present data both from our own investigations into human tumours and from the literature which indicate antibody reactions against various components of malignant tumours, and particularly to emphasize the aspect in which the antibody may protect the host against the phase of malignancy in which circulating tumour cells play an important part.

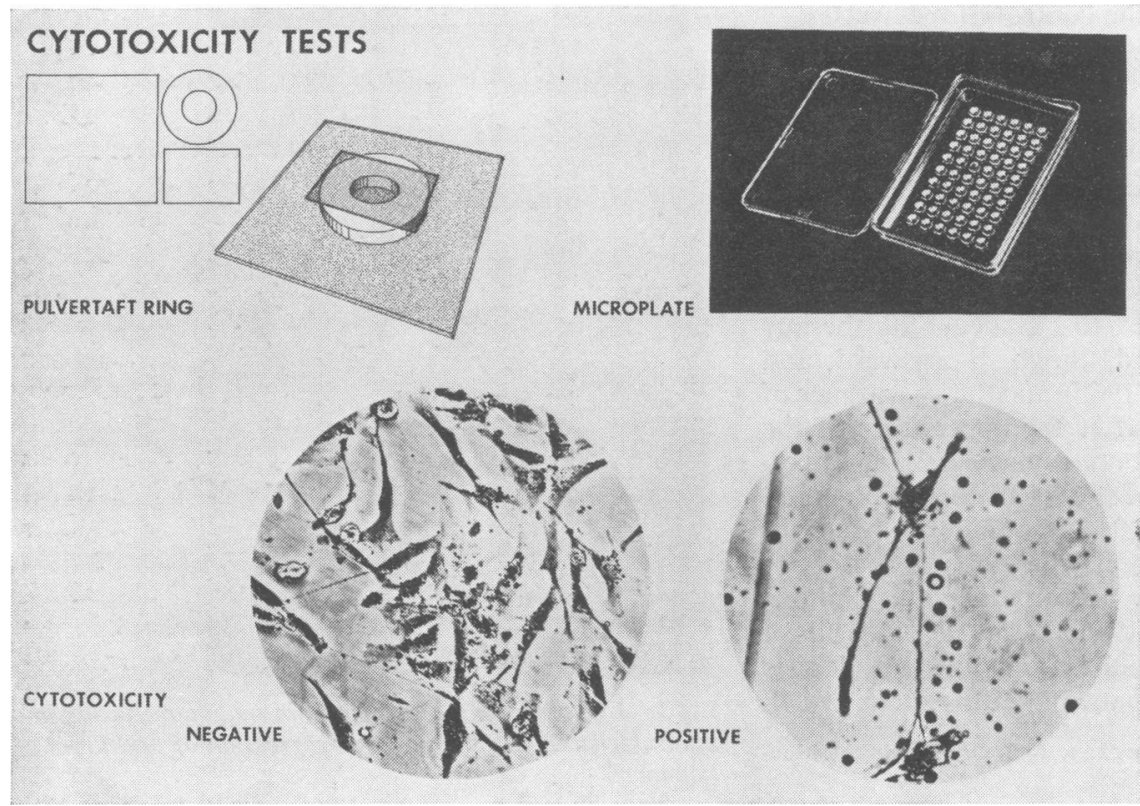

Fig 2 Examples of cytotoxicity tests using patient's serum and complement against fresh tumour cells. 


\section{The Importance of the Antigen}

The neoplastic cell, like all cells, contains numerous potential antigens. It therefore became clear that the various discrepancies and contradictions in measuring immune reactions might well result from differences in the antigens against which the immune reactions were measured. In human malignant melanoma there is evidence that several groups of antigens exist. These have been detected on the cell surface, in the cytoplasm, and in nuclear and nucleolar structures.

\section{CELL SURFACE ANTIGENS}

Studies on several human tumours have indicated the possibility of a series of antigens located on the surface of the cell. In some studies of human melanoma a strongly expressed patient-specific antigen has bein detected (fig 3) by means of immunofluorescence and cytotoxicity, as well as a much weaker and cross-reacting antigen usually at a lower level of intensity (Lewis et al, 1969; Lewis and Phillips, 1972a). In other tumours, such as sarcoma and osteogenic sarcoma, the main surface antigen appears to crossreact uniformly at a high intensity, in that the antibody detectable against this antigen is present in most patients and reacts against autologous and heterologous cells with equally high titres (Morton, Malmgren, Hall, and Schidlovsky, 1969; Morton, Eilber, Joseph, Wood, Trahan, and Ketcham, 1970). It has been suggested that the differences might be explained on the basis

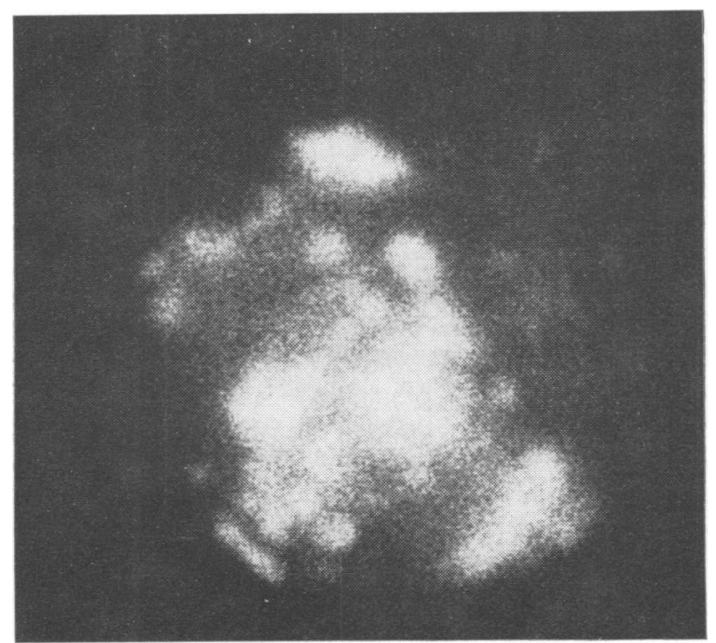

Fig 3a of viral versus chemical induction of such antigens but this is still open to further studies. Recent investigations have also suggested the presence of yet another type of antigen located on the surface of some malignant cells which has the features of a so-called carcinoembryonic antigen (Coggin, Ambrose, Bellomy, and Anderson, 1971; Ting, Lavrin, Shiu, and Herberman, 1972). In some preliminary studies we have shown that fetal type antigens may be expressed on the surface of several human tumours which are distinguishable from other tumour-specific antigens present on the same cell. Even with the data so far presented it can be seen that with the variety of antigens possible and the multitude of methods of detecting immunity against them that differences in interpretation are bound to occur.

\section{CYTOPLASMIC ANTIGEN}

When melanoma cells are prepared by snapfreezing on glass so that the cytoplasmic contents become available to the serum reaction, the presence of yet another type of antigen has been demonstrated (Lewis et al, 1969; Phillips and Lewis, 1970) (fig 4). In this case, there appeared to be a cross-reacting antibody against the antigen which is not unique and can occur at high titres in a number of patients, the indication being that this is a group-specific antigen. In determining how universal and common this particular antigen is, considerably larger series of studies will have to be carried out. There is a suggestion again that more than one type of group-

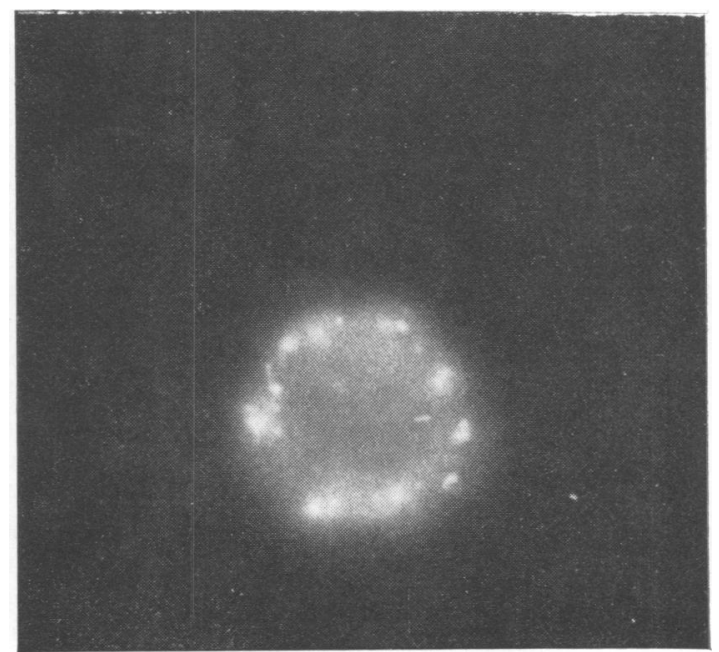

Fig $3 b$

Fig 3 Surface membrane antigens on malignant cells detected with (a) indirect immunofluorescence, using an epillumination, and $(b)$ auorescence microscope. 


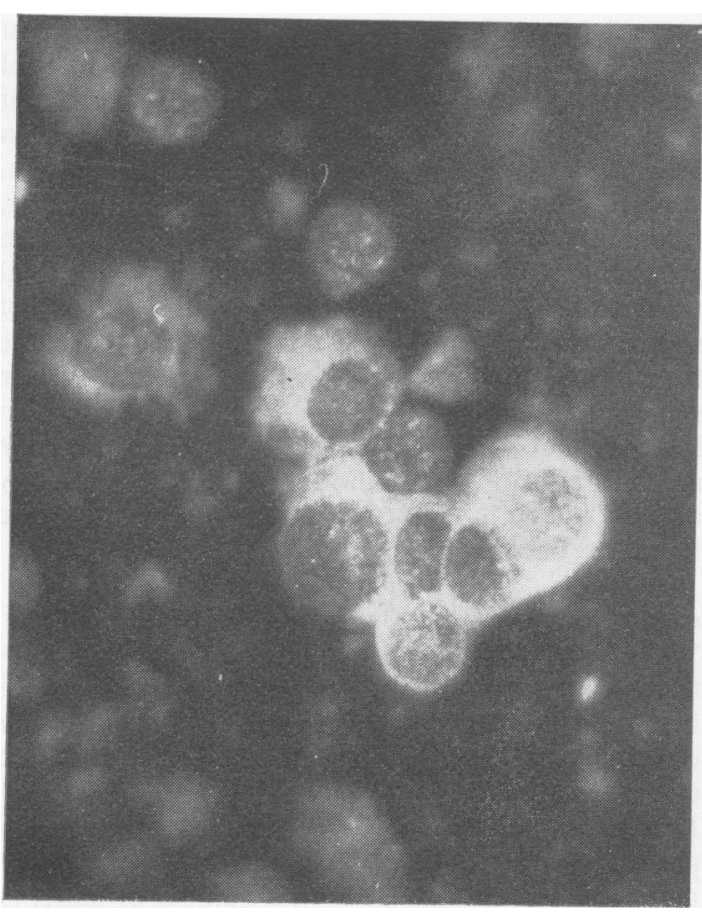

Fig 4a

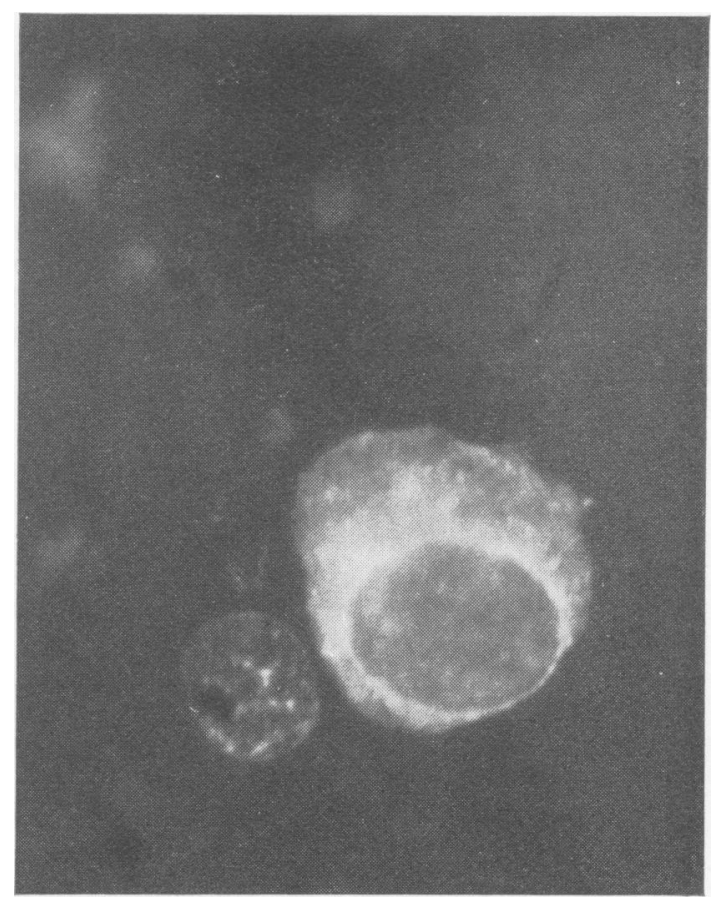

Fig 4b

Fig $4 \mathrm{a}$ and $\mathrm{b}$ Cytoplasmic antigens located by immunofluorescence on snap-frozen cells attached to glass.

specific antigen may occur and that the antibodies against these antigens may also appear at different stages in the disease process. Individual patients appear to have antibodies against both cytoplasmic antigen and membrane antigen at any one time and since these have different specificities this suggested a study whereby it was possible with cross-absorption techniques to separate the antibodies against these two components (Lewis and Phillips, 1972b). However, sera from patients with either very early melanomas or melanomas that have been excised and not recurred sometimes show no antibody reaction against allogeneic cells using the cytoplasmic technique. It is possible, therefore, that both autologous and allogeneic cytoplasmic antigen exists and that appropriate antibodies are present against these at different stages of the disease. A recent study has added yet another antigen to the list in that $45 \%$ of 140 patients with melanoma when tested by the fluorescent antibody technique using their own sera showed a clear reaction with what appears to be the nucleolus of the melanoma cell (McBride, Bowen, and Dmochowski, 1972). The antibody against this particular antigen again appears to have a different specificity from that detectable against the membrane or cytoplasmic antigens.

\section{The Specificity of Antibody/Antigen Reactions}

It is first necessary to establish that the antibody/ antigen reaction takes place against a component of the tumour and not against components of normal tissue, thus establishing tumour specificity. This has been approached in a number of ways. For instance, the positive sera have been shown not to react with the surface of other tumour cells, normal cells, or fetal cells, and absorption of the sera by the tumour considerably reduces or abolishes the reaction whereas absorption with normal tissues and other neoplastic tissues does not reduce the reactions significantly. In melanoma this was carried out using the patient's own skin, pigmented skin, and a variety of other absorbent materials prepared from various tissues (Lewis et al, 1969; Lewis, 1973) (table I). A possibility of coexisting antinuclear factor has been excluded by using a variety of cell preparations standard in the antinuclear factor test (Hijmans, Schuit, Mandema, Nienhuis, Feltkamp, Holborow, and Johnson, 1964). The next step was 


\begin{tabular}{lllll}
\hline & $M E L 1$ & $M E L ~$ & $M E L ~$ & $M E L 4$ \\
\hline Bovine liver & $1 / 32$ & $1 / 32$ & $1 / 32$ & $1 / 32$ \\
Rat liver & $1 / 32$ & $1 / 32$ & $1 / 32$ & $1 / 32$ \\
Melanin granules & $1 / 32$ & $1 / 64$ & $1 / 32$ \\
Human skin (non-pigmented) & $1 / 32$ & $1 / 64$ & $1 / 32$ & $1 / 32$ \\
Human skin (heavily pigmented) & $1 / 32$ & $1 / 32$ & $1 / 32$ & $1 / 32$ \\
Human skin (pooled) & $1 / 32$ & $1 / 64$ & $1 / 32$ & $1 / 32$ \\
Autologous skin & $1 / 32$ & $1 / 64$ & $1 / 32$ & $1 / 32$ \\
Allogeneic melanoma extract & $1 / 8$ & $1 / 8$ & $1 / 16$ & 0 \\
Autologous melanoma extract & $1 / 2$ & $0 / 0$ & $0 / 0$ & 0 \\
\hline
\end{tabular}

Table I Specificity of antibody against malignant melanoma, demonstrated by the inability of a variety of tissues, apart from melanoma tumour, to absorb out the reaction

\begin{tabular}{llllllll}
\hline Patients' Cells & \multicolumn{3}{l}{ Corresponding } & Patients' Serum & & & \\
\cline { 2 - 7 } & Law & Sh & Jas & Dow & Rug & Co & Lie \\
\hline Law & $1 / 4$ & $1 / 64$ & $1 / 64$ & $1 / 32$ & $1 / 32$ & $1 / 64$ & $1 / 32$ \\
Sh & $1 / 32$ & $1 / 4$ & $1 / 32$ & $1 / 32$ & $1 / 16$ & $1 / 32$ & $1 / 64$ \\
Jas & $1 / 32$ & $1 / 32$ & $1 / 8$ & $1 / 32$ & $1 / 32$ & $1 / 64$ & $1 / 64$ \\
Dow & $1 / 8$ & $1 / 8$ & $1 / 16$ & $1 / 4$ & $1 / 16$ & $1 / 8$ & $1 / 16$ \\
Rug & $1 / 32$ & $1 / 32$ & $1 / 64$ & $1 / 32$ & $1 / 4$ & $1 / 64$ & $1 / 32$ \\
Co & $1 / 32$ & $1 / 32$ & $1 / 32$ & $1 / 32$ & $1 / 32$ & $1 / 8$ & $1 / 32$ \\
Lie & $1 / 64$ & $1 / 32$ & $1 / 32$ & $1 / 64$ & $1 / 32$ & $1 / 32$ & $1 / 4$ \\
\hline
\end{tabular}

Table II Demonstration of specificity of membrane immunofluorescence in melanoma

${ }^{1}$ Absorption of autologous cells and sera reduced the subsequent reaction; sera absorbed with any of the above cells did not reduce their reaction with their own cells.

to establish the various specificities of the individual antibodies against the different antigens of the tumour cell. In melanoma this has been achieved by means of a series of cross-absorption experiments using the membrane immunofluorescent technique on living cells. Positive sera reacting against their own autologous cells have been cross absorbed with other melanoma cells and then reapplied to the surface of the autologous cells. Under these circumstances it has been shown that the autologous cells reduce the titre of the reaction whereas absorption with the allogeneic cells produces little or no reduction in the original reaction (table II) (Lewis and Phillips, 1972a). This has not been shown to be the case with the common cytoplasmic antigen where cross absorption is effectively produced by allogeneic and autologous cells. The cytotoxic antibody also shows little cross reactivity with other melanoma cells (Lewis, 1967; Lewis et al, 1969), a fact which has been confirmed using several human melanoma cell lines (Goodwin, Hornung, Leong, and Krementz, 1972). Thus, this provides further evidence of the different specificity of antibodies against these two components of the cell. It also points the way towards an important procedure, which is physically and chemically to separate the component antigens and their respective antibodies. This will be of vital importance in finally understanding and measuring the various components during the evolution of the neoplastic process.

\section{Relationship between the Presence of Antibody and the Development of Malignancy}

The significance of the presence of antibody against any of the antigenic components described wil depend on the consistency with which they are present at different stages of the disease. Many authors in recent publications have alluded to the possibility that cell-mediated responses are the most important immunological reactions against malignant disease. This may well be the case if one is considering the rejection of tumour already established either as a primary or as metastatic deposits. It might also be appropriate in considering the initial change from a 'benign' lesion to malignant tumour. The presence of antibody in the circulation directed against circulating tumour cells could also be of considerable importance in terms of protecting blood stream or lymph from the transit of tumour cells which ultimately give rise to metastases. Certaintly, antibodies have to be clearly defined and delineated and the relationships clearly stated. In several series cytotoxic antibody and antibody detectable by immunofluorescence and several other methods have largely been found in patients with early or localized disease and some authors have not detected antibody in the stage of dissemination (Lewis et al, 1969; Morton, Eilber, Malmgren, and Wood, 1970). In malignant melanoma the change from 
positive to negative has also been observed in many patients when studied over a period of time and it is this change in an individual which may be of the most significance. A large number of patients were investigated and extensively followed up at the Westminster Hospital and their sera reacted by means of fluorescent antibody techniques. In a number of patients the antibody levels have fallen before the appearance of metastases, and in some cases the fall in antibody level precedes the appearance of metastases by up to six months (Lewis, McCloy, and Blake, 1973). This certainly suggests a positive role for at least one particular antibody in the natural process of malignant melanoma. The questions that need to be answered are, 'Which antibody against which antigen, and at which moment in time?' This will require a considerable number of detailed sequential studies in which individual patients act as their own controls during the course of their disease.

Mechanisms for Loss of Circulating Antibodies in Malignancy

The assumption that the circulating antibody can play a significant role in the control of metastatic spread of tumours naturally leads one to pose the question, 'Why should the antibody disappear, particularly at the stage when it appears to be most needed?' The following is a résumé of investigations designed to answer this question and also to emphasize the importance of having a more specific characterization of the types of antigens involved in the malignant process and the type of antibody directed against them. The first two possible mechanisms to explain the fall in antibody and the spread of tumour could be a lack of responsiveness on the part of the host or an alteration in the immunogenicity of the tumour. If either or both of these was the answer then the patient should not respond to immunization with his own irradiated tumour cells in the late stage of the disease. Several series have been reported, however, of patients receiving such immunization programmes in which both humoral antibody and cellular immune responses were obtained (Çurrie, Lejeune, and Fairley, 1971; Ikonopisov et al, 1970; Morton, Eilber, Malmgren, and Wood, 1970; Krementz, Samuels, Wallace, and Benes, 1971) In one series of malignant melanoma patients, a typical secondary type of response with IgG rising rapidly in the serum followed immunization, but it only persisted for approximately two to three weeks (fig 5). Further repeated immunizations also showed a subsequent rise in antibody of the same type. It is clear from these experiments that the patient is capable of recognizing the antigen again and responding effectively. The remaining tumour deposits, however, in these patients showed no appreciable alteration (Lewis, McCloy, Blake, and Phillips, 1973), and, although some authors have claimed a favourable response from this approach, in most cases this was obtained in patients in whom the bulk, if not all, of the clinically detectable tumour had been removed (see Morton, Haskell, Pilch, Sparks, and Winters, 1972).

\section{Auto-Immunisation (fumour cells only)}

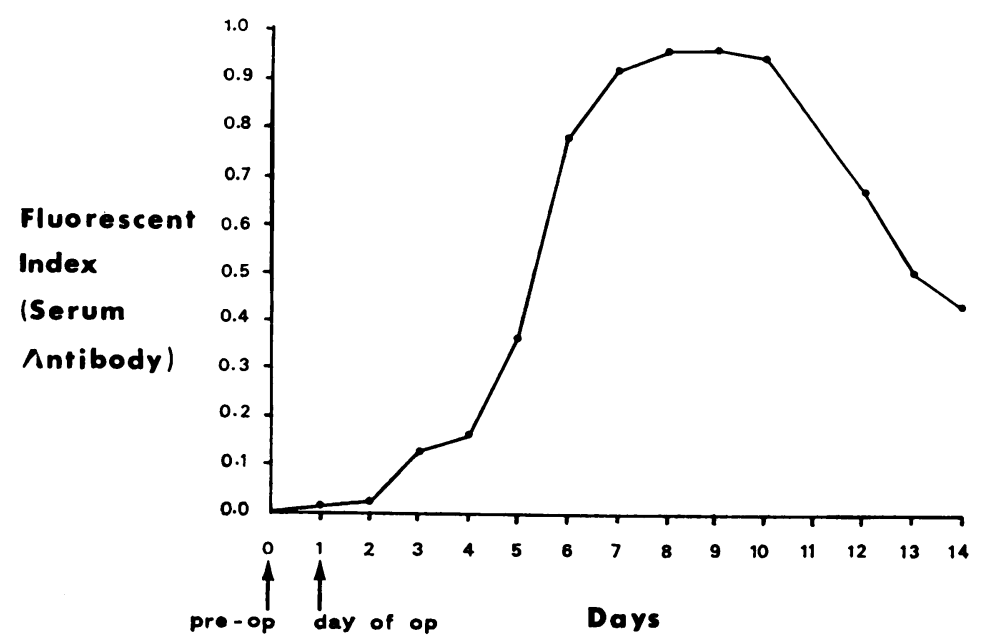

Fig 5 Rapid rise in antibody following immunization with autologous irradiated tumour cells. 
The other question posed by these experiments was why the antibody raised in immunization also disappeared. The next possible mechanism to be considered is one in which the antibody is being effectively neutralized by a rapidly developing tumour, either because the antibody is being soaked up on the surface of remaining tumour masses or as a result of circulating soluble antigen liberated by such a tumour. To investigate the validity of the first of these possibilities patients with malignant melanoma were immunized with their own irradiated tumour cells, the sera collected in the usual way daily, following the procedure, and biopsies taken of remaining tumour nodules before immunization, during the height of the antibody response, and at the end of the investigation. These tumour cells were subjected to direct immunofluorescence in an attempt to demonstrate antibody on the surface of the cells; the cells were also subjected to an elution procedure in which any immunoglobulin even in very small quantities could be removed, concentrated, and detected by immunodiffusion or immunoelectrophoretic methods on cellulose acetate membrane (Phillips and Lewis, 1971). The results have clearly shown that no detectable change occurs in even the smallest subcutaneous nodules following immunization alone. This may mean that the antibodies have some difficulty in reaching the deposits in the extravascular tissues. Another approach has been to attempt to coat tumour nodules with immunoglobulin by other methods. This was stimulated by a preliminary investigation where the administration of intravenous phytohaemagglutinin to a patient with multiple cutaneous and subcutaneous melanoma resulted in the tumour nodules exhibiting heat, swelling, pain, and reduction in size. Biopsy showed that the tumour nodules were infiltrated with lymphoid cells and that the tumour cells were heavily coated with immunoglobulin. These antibodies were in fact easily detectable and easily eluted from the cell (Lewis, Humble, Lee, and Phillips, 1971). A series of patients were, therefore, given either intravenous phytohaemagglutin alone or in combination with tumour 'autoimmunization' whilst a control group received 'autoimmunization' alone: this clearly indicated that only in the patients receiving intravenous phytohaemagglutinin did the extravascular tumour deposits become coated, and in all cases accompanied by lymphoid infiltration (Lewis et al, 1973). This shows that under normal circumstances the antibody does not become 'soaked up' by tumours outside the blood stream.

\section{Investigation of Blocking Factors in Serum}

The final possibility to explain the fall in antibody seemed to revolve around the possibility of a substance in the serum which could block the effectiveness of circulating antibody against tumour cells. In an attempt to demonstrate this three patients who had received immunization with their irradiated tumour cells were studied, and the high-titre positive sera obtained between 10 and 14 days following immunization were mixed with equal volumes of the series of control sera including normal human sera and sera from other melanoma patients; this resulted in very little alteration in the antibody response by membrane immunofluorescence or by cytotoxicity. On the other hand, the same positive serum mixed with the negative serum from the same patient taken the day before 'autoimmunization' resulted in a complete blocking of the positive serum. The positive sera, however, could not be blocked by the negative serum from the other two patients, and in addition only the surface membrane reaction was abolished; the antibody against the cytoplasmic component was not involved. Separation of the two sera into their gamma and nongamma fractions revealed that the reaction took place between the gamma globulin fraction of the negative serum and the gamma globulin fraction of the positive serum. Separation of the negative serum gamma globulin fraction into its immunoglobulin subclasses revealed that the active blocking substance was IgG. The reactions still took place even when a highly purified IgG was obtained on a DEAE cellulose column, and subsequent immunoelectrophoresis with the negative IgG against the positive IgG, and against anti-IgG and antihuman again indicated one very narrow line of reaction in which no other component in the negative IgG could be demonstrated. This procedure was carried out at several $\mathrm{pH}$ ranges in an attempt to separate the negative IgG from possible links with antigen, and the reaction was identical to that described previously (Lewis, Phillips, Cook, and Blake, 1971). The possible explanations for this phenomenon are: (1) The negative IgG is, in fact, an antibody-antigen complex in which there is excess antigen but in which the antigen is very firmly bound to the IgG molecule in such a way that it cannot be separated by the procedures described. (2) The IgG represents an anti-idiotype or anti-antibody against the original tumour-specific antibody. This particular phenomenon has been described on several occasions and has also been shown in a totally unrelated system, namely, the antibody against bacteria in rabbits (Drew, Thompson, and Pardoe, 1972). This phenomenon, although possibly similar to the blocking factor described by Hellström and Hellström (1971) and by Bansal and Sjögren (1971), differs in the site of action, the latter blocking the 
effect of cytotoxic lymphocytes on the target cells.

To be able to clarify the possible role of antigen in this reaction more knowledge is needed of the actual antigens involved. In one preliminary experiment we produced an antibody-antigen complex by reacting a positive melanoma serum with the surface membrane of the autologous cells, and by ultrasonication produced an antibody-antigen complex with antigen excess. This would, as expected, block or neutralize the positive antibody-containing serum, but showed no cross-reactivity with the negative serum in the same patient. This indicates that not all tumourspecific antibody-antigen complexes can be regarded as responsible and, therefore, the possibility of an anti-idiotype must still be considered. If this is subsequently shown to be the case it presents some very interesting possible lines of approach in the understanding of this failure of humoral immunity, and also opens up several interesting channels of research in terms of subsequent immunotherapy; for if the anti-antibody can be prevented then the tumour antibodies theoretically should persist and this should increase the resistance to circulating tumour cells.

\section{Other Aspects of the Interplay between Antibody and Tumour Antigens}

\section{RENAL COMPLICATIONS}

The discussion so far has indicated that antibodies and antigens react in patients with malignancy and there is some suggestion that such reactions can be either beneficial or detrimental depending on the timing, the type of antibody, and the antigen concerned Whatever the outcome in terms of the patient's survival, it would seem possible that antibody-antigen complexes might be deposited in the reticuloendothelial system or even on the basement membrane of the kidney. The latter would be particularly likely if the patient were producing small amounts of antibody and antibody-antigen complexes were therefore being produced with excess antigen. This is a situation which has been shown to result in deposition of antibody-antigen complexes on the basement membrane of the kidney.

THE NEPHROTIC SYNDROME AND MALIGNANCY There are now several reports of the association between a progressive nephrotic syndrome and longstanding malignancy (Cantrell, 1969; Loughridge and Lewis, 1971). In some cases the relationship between the two is not clear whereas in others the nephrotic syndrome has temporarily abated on removal of the tumour (Cantrell, 1969; Ghosh and Muehrcke, 1970). In view of this and the considerable theoretical possibilities of antibody-antigen

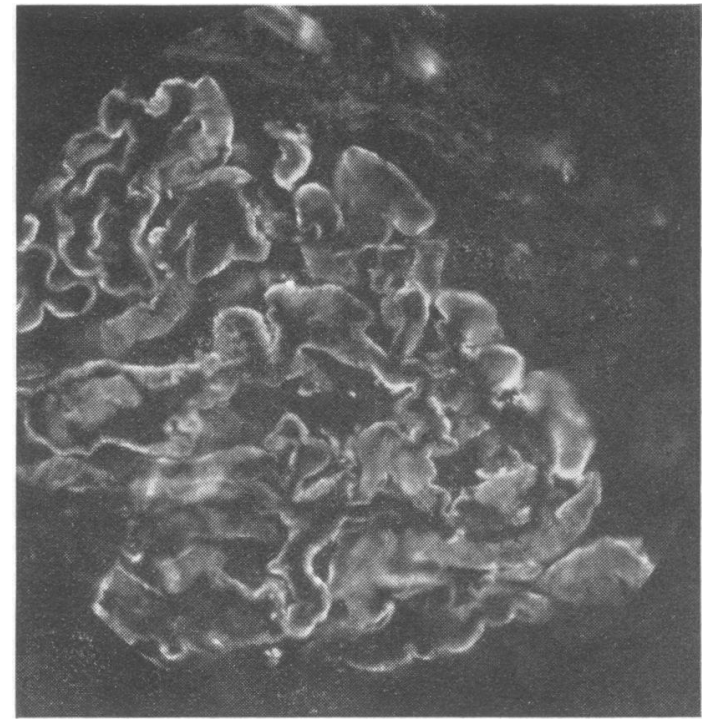

Fig 6 Direct immunofluorescence on glomerulus of patient with the nephrotic syndrome and malignancy, with lumpy distribution of immunoglobulin on basement membrane.

complex deposition occurring in patients with malignancy it was decided to investigate a patient who developed a classical nephrotic syndrome following the appearance of carcinoma of the lung which, although considered inoperable, remained clinically static for a period of some years. Biopsy of the kidney showed an epimembranous nephropathy and immunofluorescence revealed the presence of immunoglobulin in a 'lumpy-bumpy' distribution on the basement membrane (fig 6). The patient died and it was possible to obtain viable tumour cells from the lung and kidney in a fresh state. Material eluted from the kidney containing immunoglobulin reacted specifically by membrane fluorescence with the carcinoma of the lung cells but not with other cells taken from the same patient or other patients. The reaction could be abolished by absorption with the lung tumour but not by absorption with lung tissue. A reaction between an extract of the lung tumour, the elute from the kidney, and the patient's serum produced on immunodiffusion a line of identity between the sera and the elute from the kidney against the extract from the lung tumour (Lewis, Loughridge, and Phillips, 1971). Similar observations have been reported in experimental animal models with lymphomas (Mellors, 1966; Mellors, Shirai, Aoki, Haebner, and Krawczynski, 1971) and there appears to be an increasing aware- 
ness of minor degrees of the nephrotic syndrome in malignancy. The suggestion is that under the conditions described previously slowly forming complexes between tumour-specific antibody and some tumour antigens result in deposition in the kidney with subsequent damage and the production of the nephrotic syndrome. The inevitable question is immediately raised as to why the nephrotic syndrome does not occur more frequently. However, there is the possibility that minor degrees of the nephrotic syndrome could easily be overlooked in patients with advanced malignancy, and the timing of the events is obviously critical. Further studies into this particular aspect of antibodies and antigens in malignancy is of considerable interest not only because the kidney may well act as a very effective bioabsorption column for obtaining antigens and antibodies, but this particular model may also serve to further our understanding of immune complex diseases of the kidney. This aspect of the studies also carries a note of warning: there is a tendency for immunotherapeutic approaches to be used on a wide scale despite the fact that we understand little about the basic mechanisms involved. The use, for instance, of blood transfusion and the transfusion of large volumes of serum from patients whose tumours appear to be regressing into patients with progressing tumours (Horn and Horn, 1971) depends on the surface antigen being equally represented from one patient to another-a situation certainly not seen in some human tumours. The danger of forming antibody-antigen complexes which could result in considerable damage to the kidney must also be considered.

The value and dangers of the hyperimmune state in malignancy might well be worthy of investigation. There are now numerous examples, the best of all perhaps being the hyperimmune situation in chronic endemic malaria, where considerable derangements of the immune system result from the hyperimmune state or are associated with the hyperimmune state. The deposition of immunoglobulin complexes in chronic malaria resulting in the nephrotic syndrome on the one hand (Kibukamusok, Hutt, and Wilks, 1967) and so-called big spleen disease or tropical splenomegaly on the other has certain interesting parallels with the situation beginning to emerge from some examples of the malignant process (Ziegler, Cohen, and Hutt, 1969). There could, therefore, be some interesting parallels in the study of immunity to parasites, such as the plasmodia, and circulating tumour cells. Widespread attempts at immunotherapy, particularly those involving passive immunity, should be preceded by further investigations into these aspects of the immune response against tumour cells.

\section{Antibodies not Involved in Protective Immunity}

As stated at the beginning of this discussion it is not inconceivable that antibodies could be produced against components of the tumour cell-rather like components of bacteria, viruses, and protozoawhich have not primarily a protective function but are dependent on other immune processes. The antibody cytoplasmic components might well be considered under such a heading since it is unlikely that antigens expressed by internal components of cells could initially be involved in a protective immune function. Before dismissing this entirely, however, it is worth remembering that the process of emperipolysis described by Pulvertaft (1959) apparently shows that lymphocytes may enter the living cells and emerge without destroying the cell. Perhaps this could be considered an immune surveillance even against internal antigens and, therefore, might explain some of the discrepancies in the presence of antibody against internal antigens at different stages of the malignant process. The value, nevertheless, of being able to detect antibodies against cytoplasmic or nucleolar antigens lies mostly in the diagnostic aspect; they may also be of considerable use in following the progress of a patient with malignant disease with no readily available autologous tumour. A series of investigations is at present being carried out to determine how common the cytoplasmic antigen described previously in malignant melanoma may be, and how useful the antibodies against this antigen are in terms of diagnosis, prognosis, and follow up. Initial studies have indicated that antibodies against this antigen are not found in the sera of patients with a variety of skin tumours including, interestingly enough, juvenile melanomas, but are present in the sera of patients with early malignant melanoma (table III). There have now been 15 patients with the so-called halo-naevus syndrome studied by means of the cytoplasmic antigen of melanoma cells (Lewis and Copeman, 1973). This has revealed the presence of antibody crossreacting with cytoplasmic contents of malignant melanoma cells in the sera of patients with the active phase of halo naevus, but not present four or five months or years later when the active process has declined. It has been suggested that the halo naevus has an immunological basis and these preliminary studies might well indicate a much closer relationship between this peculiar disappearing naevus with its halo of depigmentation and malignant melanoma in its early stages (Copeman, Lewis, and Bleehan, 1973). The possibility that the halo naevus (fig 7) is in fact a melanoma at a very early stage being rejected is also supported by the dense lymphocytic infiltration seen in this lesion. There are, how- 


\begin{tabular}{lclc}
\hline $\begin{array}{l}\text { Histological Classification } \\
\text { of Skin Lesion }\end{array}$ & $\begin{array}{l}\text { Total No. } \\
\text { Tested }\end{array}$ & \multicolumn{2}{c}{ Immunofluorescence Results } \\
\cline { 3 - 4 } & & No. + ve & No. - ve \\
\hline Basal cell carcinoma & 62 & 1 pigmented & 61 \\
Basal cell papilloma & 17 & BCC & 17 \\
Squamous cell carcinoma & 6 & & 6 \\
Keratoacanthoma & 6 & & 6 \\
Epidermoid- & 15 & & 15 \\
sebacous cysts & 10 & & 10 \\
Senile keratosis & 14 & & 14 \\
Pigmented naevi (various) & 3 & & 3 \\
Juvenile melanoma & 4 & & 26 \\
Primary melanoma & 26 & & 158 \\
Miscellaneous & 163 & 5 & \\
Total & &
\end{tabular}

Table III Results of testing sera from a variety of skin tumours against cytoplasmic antigens of malignant melanoma cells by immunofluorescence

ever, some unexplained features; for instance, the loss of secretory melanocytes at the periphery of the lesion and the antibody detected is against the common cytoplasmic antigen. This could be explained purely on the basis that the production of this antibody is in fact a secondary phenomenon and that a primary immune response against the tumour is cell-mediated-thus rejection and the destruction of tumour cells with the liberation of cytoplasmic contents causes a secondary rise in antibody against cytoplasmic antigen. The absence of melanocytes on the periphery of such lesions, however, and some recent findings that sera from patients with the halo naevus can be cytotoxic even against normal human melanocytes (Bleehan, 1972, personal communication) suggests that more than one antibody may be involved and that at least one may be cyto-

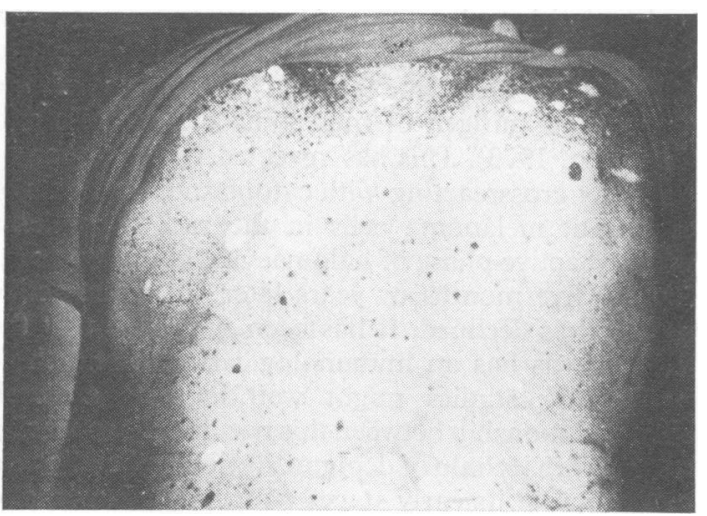

Fig 7 Multiple halo naevi and regressing malignant melanoma in the same patient (by kind permission of Dr Wallace Clark of Temple University, Philadelphia, USA). toxic. Further investigation into this subject may be of considerable importance in understanding the interaction between tumour and host at its very earliest stage.

\section{References}

Armstrong, D., Henle, G., and Henle, W. (1966). Complementfixation tests with cell lines derived from Burkitt's lymphoma and acute leukemias. J. Bact., 91, 1257-1262.

Arpels, C., and Southam, C. M. (1969). Cytotoxicity of sera from healthy persons and cancer patients. Int. J. Cancer, 4, 548-559.

Bansal, S. C., and Sjögren, H. O. (1971). 'Unblocking' serum activity in vitro in the polyoma system may correlate with anti-tumour effects of antiserum in vivo. Nature [new Biol.], 233, 76-78.

Bodenham, D. C. (1968). A study of 650 observed malignant melanomas in the south-west region. Ann. roy. Coll. Surg. (Engl.), 43, 218-239.

Cantrell, E. G. (1969). Nephrotic syndrome cured by removal of gastric carcinoma. Brit. med. J., 1, 739-740.

Clifford, P., Singh, S., Sternswärd, J., and Klein, G. (1967). Longterm survival of patients with Burkitt's lymphoma-an assessment of treatment and other factors which may relate to survival. Cancer Res., 27, 2578.

Coggin, J. H., Jr., Ambrose, K. R., Bellomy, B. B., and Anderson, N. G. (1971). Tumour immunity in hamsters immunized with faetal tissues. J. Immunol., 107, 526-533.

Copeman, P. W. M., Lewis, M. G., and Bleehan, S. S. (1973). Biology and immunology of vitiligo and cutaneous malignant melanoma. In Recent Advances in Dermatology, no. A. J. Rook, pp. 245-284. Churchill Livingstone, Edinburgh and London.

Currie, G. A., Lejeune, F., and Fairley, G. H. (1971). Immunization with irradiated tumour cells and specific lymphocyte cytotoxicity in malignant melanoma. Brit. med. $J$. 2, 305-310.

Drew, R. L., Thompson, S., and Pardoe, G. I. (1972). The immunogenicity of Proteus vulgaris OX19 in the rabbit. Path. et Microbiol. (Basel), 38, 184-191.

Ehrlich, P. (1957). Uber den jetzigen Stand der Karzinomforschung (1909). In The Collected Papers of Paul Ehrlich, compiled and edited by $F$. Himmelweit, vol. 2, Immunology and Cancer Research, p. 550-562. Pergamon Press, London

Eve, F. (1903). A lecture on melanoma. Practitioner, 70, 165-174.

Everson, T. C., and Cole, W. H. (1966). Spontaneous Regression of Cancer. Saunders, Philadelphia and London.

Foley, E. J. (1953). Attempts to induce immunity against mammary adenocarcinoma in inbred mice. Cancer Res., 13, 578-580.

Ghosh, L., and Muehrcke, R. C. (1970). The nephrotic syndrome: a prodrome to lymphoma. Ann. intern. Med., 72, 379-382.

Gold, P. (1967). Circulating antibodies against carcinoembryonic antigens of the human digestive system. Cancer (Philad.), 20, 1663-1667.

Gold, P., and Freedman, S. O. (1965). Specific carcinoembryonic antigens of the human digestive system. J. exp. Med., 122, 467481.

Goldstein, G., Klein, G., Pearson, G., and Clifford, P. (1969). Direct membrane immunofluorescence reaction of Burkitt's lymphoma cells in culture. Cancer Res., 29, 749-752.

Goodwin, D. P., Hornung, M. O., Leong, S. P. L., and Krementz, E. T. (1972). Immune responses induced by human malignant melanoma in the rabbit. Surgery, 72, 737-743.

Hamilton-Fairley, G. (1969). Immunity to malignant disease in man. Brit. med. J., 2, 467-473.

Handley, W. S. (1907). The pathology of melanotic growths in relation to their operative treatment. Lancet, 1, 927-933.

Hellström, I. (1967). A colony inhibition (CI) technique for demonstration of tumour cell destruction by lymphoid cells in vitro. Int. J. Cancer, 2, 65-68.

Hellström, I., Hellström, K. E., Pierce, G. E., and Bill, A. H. (1968) Demonstration of cell bound and humoral immunity against neuroblastoma cells. Proc. nat.Acad. Sci. (Wash.), 60, 1231-1238.

Hellström, I., Hellström, K. E., Pierce, G. E., and Yang, J. P. S. (1968). Cellular and humoral immunity to different types of human neoplasms. Nature (Lond.), 220, 1352-1354.

Hellström, K. E., and Hellström, I. (1971). Some aspects of immune defence against cancer. I. In vitro studies on animal tumours. Cancer (Philad.), 28, 1266-1268. 
Horn, L., and Horn, H. L. (1971). An immunological approach to the therapy of cancer? Lancet, 2, 466-469.

Hijmans, W., Schuit, H. R. E., Mandema, E., Nienhuis, R. L. F., Feltkamp, T. E. W., Holborow, E. J., and Johnson, G. D. (1964). Comparative study for the detection of antinuclear factors with the fluorescent antibody technique. Ann. rheum. Dis., 23, 73-77.

Ikonopisov, R. L., Lewis, M. G., Hunter-Craig, I. D., Bodenham, D. C., Phillips, T. M., Cooling, C. I., Proctor, J., HamiltonFairley, G., and Alexander, P. (1970). Autoimmunization with irradiated tumour cells in human malignant melanoma. Brit. med. J., 2, 752-754.

Jehn, U. W., Nathanson, L., Schwartz, R. S., and Skinner, M. (1970) In vitro lymphocyte stimulation by a soluble antigen from malignant melanoma. New Engl. J. Med., 283, 329-333.

Kibukamusok, J. W., Hutt, M. S. R., and Wilks, N. E. (1967). The nephrotic syndrome in Uganda and its association with quartan malaria. Quart J. Med., 36, 393-408.

Klein, G., Clifford, P., Klein, E., and Stjernwärd, J. (1966). Search for tumor-specific immune reactions in Burkitt lymphoma patients by the membrane immunofluorescence reaction. Proc. nat Acad. Sci. (Wash.), 55, 1628-1635.

Kopf, A. W. (1971). Multiple keratoacanthomas. Arch. Derm., 103. 543-544.

Krementz, E. T., Samuels, M. S., Wallace, J. H., and Benes, E. N (1971). Clinical experiences in immunotherapy of cancer. Surg. Gynec. Obstet., 133, 209-217.

Lewis, M. G. (1973). Evidence for tumour specific antigens in human melanoma. In Proceedings of the 7th National Cancer Conference. Cancer (Philad.), in press.

Lewis, M. G. (1967). Malignant melanoma of the sole of the foot in Uganda: the relationship between pigmentation and malignan melanoma on the soles of the feet. Brit. J. Cancer, 21, 483-495.

Lewis, M. G. (1968). Malignant melanoma in Uganda. M.D. Thesis, University of London.

Lewis, M. G., and Copeman, P. W. M. (1973). Immunological studies in patients with the Sutton naevus syndrome. (In preparation)

Lewis, M. G., Humble, J. G., Lee, E. S., and Phillips, T. M. (1971) The effects of intravenous phytohaemagglutinin in a patient with disseminated malignant melanoma. Rev. europ. Etud. clin. biol., 16, 924-927.

Lewis, M. G., Ikonopisov, R. L Nairn, R. C., Phillips, T. M. Hamilton-Fairley, G., Bodenham, D.C., and Alexander, P. (1969). Tumour-specific antibodies in human malignant melanoma and their relationships to the extent of the disease. Brit. med. J., 3, 547-552.

Lewis, M. G., and Kiryabwire, J. W. M. (1968). Aspects of behaviour and natural history of malignant melanoma in Uganda. Cancer (Philad.), 21, 876-887.

Lewis, M. G., Loughridge, L. W., and Phillips, T. M. (1971). Immunological studies in nephoritc syndrome associated with extrarenal malignant disease. Lancet, 134-135.

Lewis, M. G., McCloy, E., and Blake, J. (1973). The significance of humoral antibodies in the localization of human malignant melanoma. Brit. J. Surg., 60, 443-446.

Lewis, M. G., McCloy, E., Blake, J., and Phillips, T. M. (1973). The production and fate of antibody following autoimmunization in human malignant melanoma. (In preparation).

Lewis, M. G., and Phillips, T. M. (1972a). The specificity of surface membrane immunofluorescence in human malignant melanoma. Int. J. Cancer, 10, 105-111.
Lewis, M. G., and Phillips, T. M. (1972b). Separation of two distinct tumor-associated antibodies in the serum of melanoma patients. J. nat. Cancer Inst., 49, 915-917.

Lewis, M. G., and Phillips, T. M., Cook, K. B., and Blake J. (1971). Possible explanation for loss of detectable antibody in patients with disseminated malignant melanoma. Nature (Lond.), 232, $52-54$

Loughridge, L. W., and Lewis, M. G. (1971). Nephrotic syndrome in malignant disease of non-renal origin. Lancet, 1, 256-259.

McBride, C. M., Bowen, J. M., and Dmochowski, L. (1972). Antinucleolar antibodies in the sera of patients with malignant melanoma. Surg. Forum, 23, 92-93.

McKenna, J. M., Sanderson, R. P., and Blakemore, W. S. (1964). Studies of the antigens of human tumours. I. Demonstration of a soluble specific antigen in HeLa cells and some human tumors. Cancer Res., 24, 754-762.

Mellors, R. C. (1966). Autoimmune disease in NZB-B1 mice. II. Autoimmunity and malignant lymphoma. Blood, 27, 435-438.

Mellors, R. C., Shirai, T., Aoki, T., Huebner, R. J., and Krawczynski K. (1971). Wild-type gross leukaemia virus and the pathogenesis of the glomerulo nephritis of New Zealand mice, J. exp. Med., 133, 113-132.

Morton, D. L., Eilber, F. R., Joseph, W. L., Wood, W. C., Traharv, E., and Ketcham, A. S. (1970). Immunological factors in human sarcomas and melanomas: a rational basis for immunotherapy. Ann. Surg., 172, 740-749.

Morton, D. L., Eilber, F. R., Malmgren, R. A., and Wood, W. C. (1970). Immunological factors which influence response to immunotherapy in malignant melanoma. Surgery, 68, 158-164.

Morton, D. L., Haskell, C. M., Pilch, Y. H., Sparks, F. C., and Winters, W. D. (1972). In UCLA Conference: Recent Advances in Oncology. Ann. intern. Med., 77, 431-454.

Morton, D. L., Malmgren, R. A., Hall, W. F., and Schidlovsky, G (1969). Immunologic and virus studies with human sarcomas. Surgery, 66, 152-161.

Muna, N. M., Marcus, S., and Smart, C. (1969). Detection by immunofluorescence of antibodies specific for human malignant melanoma cells. Cancer (Philad.), 23, 88-93.

Nairn, R. C., Nind, A. P. P., Guli, E. P. G., Muller, H. K., Rolland, J. M., and Minty, C. C. J. (1971). Specific immune response in human skin carcinoma. Brit. med., J., 4, 701-705.

Phillips, T. M., and Lewis, M. G. (1970). A system of immunofluorescence in the study of tumour cells. Rev. europ. Etud. clin. biol., 15, 1016-1020.

Phillips, T. M., and Lewis, M. G. (1971). A method for elution of immunoglobulin from the surface of living cells. Europ. $J$. clin. biol. Res., 16, 1052-1055.

Piessens, W. F. (1970). Evidence for human cancer immunity. Cancer (Philad.), 26, 1212-1220.

Prehn, R. T., and Main, J. M. (1957). Immunity to methylcholanthrene-induced sarcomas. J. nat. Cancer Inst., 18, 769-778.

Pulvertaft, R. J. V. (1959). The examination of pathological tissue in a fresh state. In Modern Trends in Pathology, edited by D. H. Collins, pp. 19-44. Butterworth, London.

Smithers, D. W. (1964). On the Nature of Neoplasia in Man, p. 115 Livingstone, Edinbrugh and London.

Ting, C. C., Lavrin, D. H., Shiu, G., and Herberman, R. B. (1972). Expression of fetal antigens in tumor cells. Proc. nat. Acad. Sci. (Wash.), 69, 1664-1668.

Ziegler, J. L., Cohen, M. H., and Hutt, M. S. R. (1969). Immunological studies in tropical splenomegaly syndrome in Uganda. Brit. med. J., 4, 15-17. 